\title{
Identifying the Risk Factors for Mortality in Patients with Cancer and COVID-19 in Hamadan, the West of Iran
}

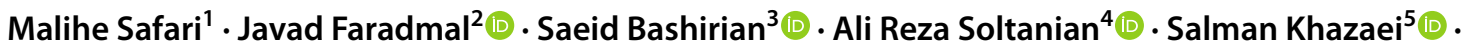 \\ Ghodratollah Roshanaei ${ }^{6}$ (D)
}

Accepted: 21 July 2021 / Published online: 4 August 2021

(c) Springer Science+Business Media, LLC, part of Springer Nature 2021

\begin{abstract}
Purpose Since cancer patients are at higher risk of COVID-19, the present study was conducted to investigate the epidemiology of these patients and identify the affecting risk factors on their mortality.

Methods The present retrospective cohort study was conducted on 66 hospitalized patients with cancer and COVID-19 in Hamadan in 2020. In the present study, demographic, clinical, and laboratory information and patients' outcome were collected through a checklist and its impact on death was assessed. Data were analyzed in SPSS-24 software and the significance level of the tests was considered at $5 \%$.

Results The mean (standard deviation (SD)) age of patients was 61.6 (13.5) years. Forty patients (60.6\%) were male. Twenty and five patients (37.9\%) died at the end of study. The results of logistic regression model revealed that the nausea, mechanical ventilation, admission to ICU, and length of hospital stay in the ward had a significant impact on the odds of death among cancer patients with COVID-19 $(p<0.05)$.

Conclusion Owing to high mortality rate in cancer patients with COVID-19 and due to underlying diseases and more severe clinical symptoms than other patients with coronavirus, these patients need intensive care and specific treatments. However, screening these patients and early identifying and vaccinating of them can reduce the mortality rate in these patients.
\end{abstract}

Keywords Cancer $\cdot$ COVID-19 $\cdot$ Logistic regression $\cdot$ Mortality $\cdot$ Coronavirus

\section{Introduction}

Cases of pneumonia with unknown causes were first reported in Wuhan, China, in December 2019 and a new type of coronavirus was identified in January 2020 [1]. The World Health

Ghodratollah Roshanaei

gh.roshanaei@umsha.ac.ir

Malihe Safari

Malihesafari97@gmail.com

Javad Faradmal

J80f@yahoo.com

Saeid Bashirian

s-bashirian@umsha.ac.ir

Ali Reza Soltanian

soltanian@umsha.ac.ir

Salman Khazaei

salman.khazaei61@gmail.com

1 Department of Biostatistics, School of Public Health, Hamadan University of Medical Sciences, Hamadan, Iran
Organization (WHO) named it COVID-19 [2]. The WHO declared the outbreak of COVID-19 as a pandemic in March 11, 2020 [3]. The first case of this virus was confirmed in Iran on February 19, 2020 [4]. As cancer patients are vulnerable populations during the COVID-19 epidemic period

2 Department of Biostatistics, School of Public Health, Modeling of Noncommunicable Diseases Research Center, Hamadan University of Medical Sciences, Hamadan, Iran

3 Social Determinants of Health Research Center, Hamadan University of Medical Sciences, Hamadan, Iran

4 Modeling of Noncommunicable Diseases Research Center, School of Public Health, Hamadan University of Medical Sciences, Hamadan, Iran

5 Research Center for Health Sciences, Hamadan University of Medical Sciences, Hamadan, Iran

6 Department of Biostatistics, School of Public Health, Modeling of Noncommunicable Diseases Research Canter, Hamadan University of Medical Sciences, Hamadan, Iran 
and often suffer immunosuppression due to the underlying disease and side effects of treatments, this group of patients is at risk for opportunistic infections. They also are at greater risk of severe complications in the case of being infected with a variety of diseases and need to be admitted to the intensive care unit (ICU) and the risk of mortality is high in this group [5-7]. COVID-19 virus may worsen the condition of patients with underlying diseases and even lead to death. Cancer, as one of the leading causes of death in the world, has been considered a risk factor in patients with COVID-19 [8].

Evidence suggests that cancer patients are more susceptible to COVID-19 than other group of people and the rate of mortality in these patients is higher than that in the people without a history of cancer [9-11]. Studies on cancer patients with COVID-19 suggest that various factors such as age, gender, underlying diseases such as hypertension, chronic lung disease, and diabetes may affect the death of cancer patients with COVID-19 [12-18]. Since few studies have been conducted on cancer patients with COVID-19, the present study aimed at evaluating the different demographic, clinical, and laboratory characteristics of these patients and identifying the factors affecting the death of this subgroup of population in Hamadan province.

\section{Methods}

\section{Study Population}

In this retrospective cohort study, 66 hospitalized cancer patients with COVID-19 in Hamadan province, the west of IRAN, were assessed.

\section{Covariates}

Demographic, clinical, and laboratory characteristics of patients, including gender, age of diagnosis, clinical symptoms, measures taken, underlying diseases, and laboratory results were extracted from patients' medical records. In this study, patients with positive real-time reverse transcriptase polymerase chain reaction (RT-PCR) on samples from upper respiratory nasopharyngeal swabs were enrolled to the study.

\section{Statistical Analysis}

Chi-square test was used to compare qualitative variables and Student's $t$ test was used for quantitative variables. In this study, death was considered the outcome. Logistic regression model was used to estimate the odds ratio (OR) of death. Data were analyzed in SPSS-24 software and the significance level of the tests was considered at 5\%.

\section{Ethics Statement}

The proposal of this study was approved by the Institutional Review Board (IRB) of Hamadan University of Medical Sciences (ethical code: IR.UMSHA.REC.1400.004).

\section{Results}

The mean (SD) and median age of patients were $61.6(13.5)$ and 63 years, respectively (range: 22-94). Forty (60.6\%) patients were male. Twenty and five (37.9\%) patients died at the end of study. Table 1 presents other demographic and clinical information of patients based on life conditions. The results of Table 1 revealed that having nausea, admission to ICU, and mechanical ventilation had a significant relationship with life condition in cancer patients with COVID-19 $(p<0.05)$. Also, length of hospital stay in patients who died in ward was statistically significantly different from that in patients who did not die $(p=0.035)$. In the present study, $58 \%$ of patients had at least one underlying disease other than cancer. The most important underlying diseases were hypertension (24.4\%) and diabetes (21.2\%). In the present study, the main symptoms in patients were shortness of breath $(54.5 \%)$, fever $(48.5 \%)$, chills $(45.5 \%)$, muscle pain (36.4\%), dry cough (28.8\%), sputum cough $(25.8 \%)$, and nausea $(22.75 \%)$. In the present study, mechanical ventilation, admission to ICU, and oxygen therapy were among the measures taken for hospitalized patients, so that $95.5 \%$ of patients received oxygen therapy, $37.5 \%$ received ICU, and $34.8 \%$ received mechanical ventilation. Table 2 presents the results of laboratory characteristics of patients based on life condition. The results of Table 2 revealed no relationship between laboratory characteristics in patients and treatment outcome $(p>0.05)$.

Logistic regression was used to investigate the effect of demographic factors, clinical, and laboratory characteristics on the odds ratio of death in these patients (Table 3 ). The results revealed that the variables of nausea, measure taken, hospitalization site $\mathrm{U}$, and length of hospitalization in ward had a significant impact on the odds of death in patients with COVID-19, so that admission to ICU increased the risk of death by 14 times. Also, in patients who were admitted to both ICU and ward, the risk of death increased by 17.9 times. In addition, in patients with nausea, the odds ratio of death decreased by $41 \%$. The odds ratio of death in patients with mechanical ventilation and simultaneously admission to ICU and the need for mechanical ventilation was 7.5 and 33.6 times more than the odds ratio of patients who only needed oxygen therapy (Table 3). 
Table 1 Demographic and clinical characteristics of cancer patients with COVID-19 according to life condition

\begin{tabular}{|c|c|c|c|c|}
\hline Variable & Category & $\operatorname{Alive}(n=41)$ & $\operatorname{Died}(n=25)$ & $p$ value \\
\hline \multirow[t]{2}{*}{ Sex } & Male & $23(57.5)$ & $17(42.5)$ & 0.34 \\
\hline & Female & $18(69.2)$ & $8(30.8)$ & \\
\hline \multirow[t]{2}{*}{ Resident } & Rural & $6(60.0)$ & $4(40.0)$ & 0.88 \\
\hline & Urban & $35(62.5)$ & $21(37.5)$ & \\
\hline \multirow[t]{3}{*}{ Age } & $<50$ & $12(75.0)$ & $4(25.0)$ & 0.34 \\
\hline & $50-70$ & $21(61.8)$ & $13(38.2)$ & \\
\hline & $>70$ & $8(50.0)$ & $8(50.0)$ & \\
\hline \multirow[t]{2}{*}{ Cancer type } & Solid tumors & $33(62.3)$ & $20(37.7)$ & 0.96 \\
\hline & Hematologic cancers & $8(61.5)$ & $5(38.5)$ & \\
\hline \multirow[t]{3}{*}{ Number of comorbidity } & 0 & $18(64.3)$ & $10(35.7)$ & 0.90 \\
\hline & 1 & $11(61.1)$ & $7(38.9)$ & \\
\hline & $>=2$ & $12(60.0)$ & $8(.040)$ & \\
\hline Smoking (yes) & & $2(66.7)$ & $1(33.3)$ & 0.87 \\
\hline Addict (yes) & & $2(50.0)$ & $2(50.0)$ & 0.61 \\
\hline Lung disease (yes) & & $3(75.0)$ & $1(25.0)$ & 0.58 \\
\hline Heart disease (yes) & & $3(60.0)$ & $2(40.0)$ & 0.92 \\
\hline $\mathrm{BP}(\mathrm{yes})$ & & $11(68.8)$ & $5(31.3)$ & 0.53 \\
\hline Diabetic (yes) & & $7(50.0)$ & $7(50.0)$ & 0.29 \\
\hline Kidney (yes) & & $1(20.0)$ & $4(80.0)$ & 0.07 \\
\hline Other (yes) & & $12(63.2)$ & $7(36.8)$ & 0.91 \\
\hline Fever (yes) & & $18(56.3)$ & $14(43.8)$ & 0.33 \\
\hline Cough (yes) & & $24(64.9)$ & $13(35.1)$ & 0.36 \\
\hline Diarrhea (yes) & & $5(83.3)$ & $1(16.7)$ & 0.26 \\
\hline Puke (yes) & & 13(86.7) & $2(13.3)$ & 0.77 \\
\hline Nausea (yes) & & $4(57.1)$ & $3(42.9)$ & 0.03 \\
\hline Chill (yes) & & $19(63.3)$ & $11(36.7)$ & 0.88 \\
\hline Asthmatic (yes) & & $20(55.6)$ & $16(44.4)$ & 0.22 \\
\hline Myalgia (yes) & & 17(70.8) & $7(29.2)$ & 0.27 \\
\hline Oxygen therapy (yes) & & $38(60.3)$ & $25(39.7)$ & 0.17 \\
\hline Admission to ICU (yes) & & $7(28.0)$ & 18(72.0) & $<0.001$ \\
\hline Mechanical ventilation (yes) & & $1(4.3)$ & $22(95.7)$ & $<0.001$ \\
\hline Age $(\operatorname{mean}(\mathrm{SD}()$ & & $61(14.0)$ & $62.4(12.9)$ & 0.68 \\
\hline $\begin{array}{l}\text { Hospitalization length in ICU } \\
(\text { mean(SD)) }\end{array}$ & & $6.5(2.2)$ & $5.9(6.1)$ & 0.78 \\
\hline $\begin{array}{l}\text { Hospitalization length in ward } \\
(\text { mean }(\mathrm{SD}))\end{array}$ & & $6.2(2.6)$ & $4.4(3.3)$ & 0.035 \\
\hline Total hospitalization length (mean(SD)) & & $7.3(3.3)$ & $7.5(4.4)$ & 0.86 \\
\hline
\end{tabular}

Then, the effect of laboratory characteristics on the treatment outcome of cancer patients with COVID-19 was examined using a logistic regression model. Its results are presented in Table 4. Although the nonstandard results of laboratory tests in all measured blood characteristics increased the risk of death in patients in the present study, only the variable of lactate dehydrogenase (LDH) had a statistically significant effect on death in patients. Table 5 presents the frequency distribution of different types of cancers in patients with COVID-19 based on the outcome of treatment, length of hospital stay, and the need for admission to ICU. In the present study, out of 66 hospitalized patients with cancer, $19.7 \%$ had leukemia and $80.3 \%$ had other cancers. Twenty and five patients (37.9\%) were admitted to ICU. More than $65 \%$ of patients had leukemia, breast, colorectal, and lung cancer. In the present study, $23.1 \%$ of patients with leukemia and $41.5 \%$ of patients with other cancers were admitted to ICU. The mean length of hospital stay in ICU among leukemia patients was 8 days. Table 6 presents the distribution of 
Table 2 Results of laboratory parameters of cancer patients with COVID-19 by life condition

\begin{tabular}{|c|c|c|c|c|}
\hline Variable & Category & $\operatorname{Alive}(n=41)$ & $\operatorname{Died}(n=25)$ & $p$ value \\
\hline \multirow[t]{3}{*}{ Hemoglobin $(\mathrm{g} / \mathrm{dl})$} & $<12$ & $7(53.8)$ & $6(46.2)$ & 0.2 \\
\hline & $12-16$ & $32(68.1)$ & $15(31.9)$ & \\
\hline & $>16$ & $19(33.3)$ & $4(66.7)$ & \\
\hline \multirow[t]{3}{*}{ Lymphocyte $(\mu \mathrm{l})$} & $<20$ & $19(54.3)$ & $16(45.7)$ & 0.44 \\
\hline & $20-40$ & $19(70.4)$ & $8(29.6)$ & \\
\hline & $>40$ & $2(66.7)$ & $1(33.3)$ & \\
\hline \multirow[t]{3}{*}{ Sodium (NA) } & $<135$ & $9(52.9)$ & $8(47.1)$ & 0.53 \\
\hline & $135-145$ & $30(63.8)$ & $17(36.2)$ & \\
\hline & $>145$ & $1(100)$ & 0 & \\
\hline \multirow[t]{2}{*}{ Potassium (K) } & $<3.5$ & $3(60)$ & $2(40)$ & 0.94 \\
\hline & $3.5-5$ & $37(61.7)$ & $23(38.3)$ & \\
\hline \multirow[t]{2}{*}{ PTT } & $<=45$ & $32(62.7)$ & $19(37.3)$ & 0.54 \\
\hline & $>45$ & $3(50)$ & $3(50)$ & \\
\hline \multirow[t]{2}{*}{ ESR (female $<10$ and male $<20$ ) } & yes & $12(54.5)$ & $10(45.5)$ & 0.37 \\
\hline & no & $29(65.9)$ & $15(34.1)$ & \\
\hline \multirow[t]{2}{*}{ Creatinine (mg/dl) } & $<=1.2$ & $32(65.3)$ & $17(34.7)$ & 0.36 \\
\hline & $>1.2$ & $9(52.9)$ & $8(47.1)$ & \\
\hline \multirow[t]{3}{*}{ BUN } & $<10$ & $5(71.4)$ & $2(28.6)$ & 0.29 \\
\hline & $10-43$ & $34(64.2)$ & $19(35.8)$ & \\
\hline & $>43$ & $2(33.3)$ & $4(66.7)$ & \\
\hline \multirow[t]{2}{*}{ SGOT (AST) } & $<=40$ & $23(65.7)$ & $12(34.3)$ & 0.23 \\
\hline & $>40$ & $12(50)$ & $12(50)$ & \\
\hline \multirow[t]{2}{*}{ SGPT (ALT) } & $<=40$ & $24(64.9)$ & $13(35.1)$ & 0.35 \\
\hline & $>40$ & $11(52.4)$ & $10(47.6)$ & \\
\hline \multirow[t]{2}{*}{ ALK-p (IU/L) } & $<=200$ & $18(62.1)$ & $11(37.9)$ & 0.77 \\
\hline & $>200$ & $15(57.7)$ & $11(42.3)$ & \\
\hline \multirow[t]{2}{*}{ Platelets } & $<150$ & $30(61.2)$ & $19(38.8)$ & 0.81 \\
\hline & $>=150$ & $11(64.7)$ & $35.3)$ & \\
\hline \multirow[t]{3}{*}{ Hematocrit } & $<36$ & $5(50)$ & $5(50)$ & 0.57 \\
\hline & $36-48$ & $33(67.3)$ & $16(32.7)$ & \\
\hline & $>48$ & $3(60)$ & $2(40)$ & \\
\hline \multirow[t]{2}{*}{ Lactate dehydrogenase (LDH) } & $313-618$ & $21(67.7)$ & $10(32.3)$ & 0.11 \\
\hline & $<313$ or $>618$ & $14(60.9)$ & $9(39.1)$ & \\
\hline \multirow[t]{3}{*}{ White blood cell (WBC) } & $<4000$ & $4(80)$ & $1(20)$ & 0.36 \\
\hline & $4000-12,000$ & $30(57.7)$ & $22(42.3)$ & \\
\hline & $>12,000$ & $7(77.8)$ & $2(22.2)$ & \\
\hline \multirow[t]{2}{*}{ Temperature $\left({ }^{\circ} \mathrm{C}\right)$} & $<=37$ & $19(76)$ & $6(24)$ & 0.09 \\
\hline & $>37$ & $22(55)$ & $18(45)$ & \\
\hline
\end{tabular}

treatments needed for cancer patients. The results showed that out of 42 patients treated, 29 patients (69\%) underwent chemotherapy.

\section{Discussion}

Demographic, clinical, and laboratory characteristics of 66 cancer patients infected with COVID-19 were evaluated in the present study and the impact of factors affecting the odds ratio of death in these patients was identified using logistic regression model.

In the present study, $60.6 \%$ of the patients were male. The percentage of gender varied in different studies, so that percent of male in other studies was between 46 and $60 \%$ [12-18]. Since the rate of cancer is higher in males than females [19] and males are more present in society than females and are more exposed to this virus, the higher rate of infection in males can be justified in this study. 
Table 3 Evaluating the effect of demographic and clinical characteristics based on logistic regression model

\begin{tabular}{|c|c|c|}
\hline Variable (reference group) & Category & OR $(95 \%$ CI $)$ \\
\hline Gender (female) & & $1.72(0.59-4.75)$ \\
\hline Age $51-70(<=50)$ & & $1.93(0.55-7.62)$ \\
\hline Age $>70(<=50)$ & & $3.1(0.67-13.41)$ \\
\hline Resident (rural) & & $0.92(0.23-3.62)$ \\
\hline Addict (yes) & & $1.23(0.12-14.5)$ \\
\hline Smoking (yes) & & $0.62(0.21-4.51)$ \\
\hline Lung disease (no) & & $2.11(0.22-8.31)$ \\
\hline Blood pressure (no) & & $1.70(0.40-4.82)$ \\
\hline Heart disease (no) & & $1.51(0.30-3.61)$ \\
\hline Diabetic (no) & & $1.91(0.67-6.30)$ \\
\hline Kidney disease (no) & & $7.6(0.81-16.70)$ \\
\hline Other disease (no) & & $0.94(0.30-2.81)$ \\
\hline Diarrhea (yes) & & $0.32(0.10-2.71)$ \\
\hline Regurgitation (yes) & & $1.31(0.31-6.20)$ \\
\hline Fever (yes) & & $1.63(0.61-4.40)$ \\
\hline Asthma (yes) & & $1.87(0.67-5.21)$ \\
\hline Myalgia (yes) & & $0.55(0.21-1.62)$ \\
\hline Nausea (yes) & & $0.59(0.05-0.92)^{*}$ \\
\hline Anorexia (yes) & & $0.82(0.10-9.81)$ \\
\hline Headache (yes) & & $0.31(0.08-2.73)$ \\
\hline Dry cough (yes) & & $0.48(0.15-1.61)$ \\
\hline Coughing (yes) & & $1.67(0.55-5.20)$ \\
\hline Chill (yes) & & $0.91(0.34-2.47)$ \\
\hline \multirow[t]{3}{*}{ Number of comorbidity } & 0 & \\
\hline & 1 & $1.15(0.34-3.89)$ \\
\hline & $>=2$ & $1.20(0.37-3.92)$ \\
\hline \multirow[t]{3}{*}{ Measures taken } & Oxygen therapy & 1 \\
\hline & $\begin{array}{l}\text { Oxygen therapy Mechanical ventila- } \\
\text { tion }\end{array}$ & $7.50(1.27-44.20)^{*}$ \\
\hline & $\begin{array}{l}\text { Oxygen therapy } \\
\text { \& Admission to ICU } \\
\text { \& Mechanical ventilation }\end{array}$ & $33.60(8.17-87.31){ }^{*}$ \\
\hline \multirow[t]{3}{*}{ Hospitalization site } & Normal ward & 1 \\
\hline & ICU & $14.31(2.75-68.56)^{*}$ \\
\hline & ICU and Normal ward & $17.90(3.84-56.81)^{*}$ \\
\hline Total hospitalization length & & $1.01(0.93-1.13)$ \\
\hline Hospitalization length in ICU & & $0.98(0.84-1.14)$ \\
\hline Hospitalization length in ward & & $0.78(0.61-0.99){ }^{*}$ \\
\hline
\end{tabular}

* Statistically significant
In the present study, no significant difference was observed between the odds ratio of death in males and females, as other studies confirm this result $[17,20]$. In this study, the mean and median ages of patients were 61.6 and 63 years, respectively. In studies carried out in European countries, the median age of patients was reported between 64 and 70 years [12-15], and in the study conducted by Yang et al. [16] in middle China, the median age of patients was 63 years. In most studies in other countries, the age of COVID-19 patients was higher than in the present study, and only the studies conducted in China have reported results similar to those of the present study. The high age of patients in other countries may be due to the higher awareness of people in these countries and more compliance with health protocols. Another reason for the high age of these patients in non-Asian countries may be due to the high average age of cancer patients in these countries. Also in this study, age did not have a significant effect on the risk of death. Other studies have achieved this result [16-18].

The mortality rate of this subgroup of patients in the present study was $37.8 \%$, which was $42.5 \%$ in males and $30.8 \%$ in females. In the studies conducted by Sorouri et al. 
Table 4 Evaluation of the effect of laboratory characteristics on the treatment outcome of cancer patients with COVID-19 using logistic regression model

\begin{tabular}{|c|c|c|}
\hline Variable & Category & OR(95\% CI) \\
\hline \multirow[t]{3}{*}{ Hemoglobin (g/dl) } & $<12$ & 1 \\
\hline & $12-16$ & $0.55(0.16-1.91)$ \\
\hline & $>16$ & $2.33(0.31-17.54)$ \\
\hline \multirow[t]{3}{*}{ Lymphocyte $(\mu \mathrm{l})$} & $<20$ & 1 \\
\hline & $20-40$ & $0.84(0.11-1.67)$ \\
\hline & $>40$ & $1.67(0.14-20.31)$ \\
\hline \multirow[t]{2}{*}{ NA } & $<135$ & 1 \\
\hline & $135-145$ & $0.64(0.21-1.96)$ \\
\hline \multirow[t]{2}{*}{ K } & $3.5-5$ & 1 \\
\hline & $<3.5$ & $1.07(0.17-6.91)$ \\
\hline \multirow{2}{*}{$\begin{array}{l}\text { Partial thromboplastin time } \\
\text { (PTT) }\end{array}$} & $<=45$ & 1 \\
\hline & $>45$ & $1.68(0.31-9.22)$ \\
\hline \multirow{2}{*}{$\begin{array}{l}\text { Erythrocyte sedimentation } \\
\text { rate }(\text { ESR) }(\text { female }<10 \text { and } \\
\text { male }<20)\end{array}$} & Yes & 1 \\
\hline & No & $1.61(0.57-4.58)$ \\
\hline \multirow[t]{2}{*}{ Creatinine (mg/dl) } & $<=1.2$ & 1 \\
\hline & $>1.2$ & $1.67(0.55-5.13)$ \\
\hline \multirow[t]{3}{*}{ Blood Urea Nitrogen (BUN) } & $<10$ & 1 \\
\hline & $10-43$ & $1.39(0.25-7.91)$ \\
\hline & $>43$ & $5.0(0.47-52.96)$ \\
\hline \multirow{2}{*}{$\begin{array}{l}\text { Aspartate Aminotransferase } \\
\text { (AST) }\end{array}$} & $<=40$ & 1 \\
\hline & $>40$ & $1.91(0.68-5.51)$ \\
\hline \multirow[t]{2}{*}{ Alanine Aminotransferase (ALT) } & $<=40$ & 1 \\
\hline & $>40$ & $1.68(0.56-4.97)$ \\
\hline \multirow{2}{*}{$\begin{array}{l}\text { Alkaline Phosphatase (ALK-p) } \\
\text { (IU/L) }\end{array}$} & $<=200$ & 1 \\
\hline & $>200$ & $1.20(0.41-3.54)$ \\
\hline \multirow[t]{2}{*}{ Platelets } & $<150$ & 1 \\
\hline & $>=150$ & $1.16(0.37-3.66)$ \\
\hline \multirow[t]{3}{*}{ Hematocrit } & $<36$ & 1 \\
\hline & $36-48$ & $0.48(0.12-1.92)$ \\
\hline & $>48$ & $1.67(0.11-5.87)$ \\
\hline \multirow[t]{2}{*}{ Lactate dehydrogenase (LDH) } & $313-618$ & 1 \\
\hline & $<313$ or $>618$ & $2.89(1.19-8.1)^{*}$ \\
\hline \multirow[t]{3}{*}{ White blood cell (WBC) } & $<4000$ & 1 \\
\hline & $4000-12,000$ & $2.93(0.31-28.2)$ \\
\hline & $>12,000$ & $2.14(0.12-16.9)$ \\
\hline \multirow[t]{2}{*}{ Temperature $\left({ }^{\circ} \mathrm{c}\right)$} & $<=37$ & 1 \\
\hline & $>37$ & $2.61(0.85-7.90)$ \\
\hline
\end{tabular}

*Statistically significant

[17], Yang et al. [16], Meng et al. [15], Tian et al. [14], Omarini et al. [21], and Guarneri [12], the rate of mortality was reported at $50.9,19.5,29.4,14,22$, and $33 \%$, respectively. In the study conducted by Liang et al. $39 \%$ died [9].
Table 5 Frequency distribution of patients by type of cancer in term of treatment outcome, length of hospitalization and admission to the ICU

\begin{tabular}{llll}
\hline Cancer type & $\begin{array}{l}\text { Dead } \\
\text { N }(\%)\end{array}$ & $\begin{array}{l}\text { ICU admission } \\
\mathrm{N}(\%)\end{array}$ & $\begin{array}{l}\text { Hospi- } \\
\text { talization } \\
\text { length } \\
\text { Mean(SD) }\end{array}$ \\
\hline Solid tumors $(\boldsymbol{n = 5 3 )}$ & $20(37.7)$ & $22(41.5)$ & $7.2(4.5)$ \\
Breast & $5(35.7)$ & $4(28.6)$ & $6.4(4.5)$ \\
Gastrointestinal & $5(33.3)$ & $7(46.7)$ & $7.0(3.6)$ \\
Lung & $2(28.6)$ & $3(42.9)$ & $8.9(6.4)$ \\
Nasopharynx & $1(50)$ & $2(100)$ & $13(9.9)$ \\
Prostate & $2(66.7)$ & $3(100)$ & $6.7(1.5)$ \\
Laryngeal & $1(50)$ & $0(0)$ & $6.5(6.4)$ \\
Other* & $4(40)$ & $3(30)$ & $10(0.0)$ \\
Hematologic can- & $5(38.5)$ & $3(23.1)$ & $8(4.2)$ \\
cers $(\mathbf{n}=13)$ & & & \\
AML & $0(0)$ & $0(0)$ & $4(0.0)$ \\
CLL & $2(25)$ & $2(25)$ & $8.3(4.5)$ \\
MM & $2(100)$ & $0(0)$ & $3.5(2.1)$ \\
Lymphoma & $1(50)$ & $1(50)$ & $9(2.8)$ \\
\hline
\end{tabular}

*The other consists of skin, cervical, liver, kidney, ovarian, thyroid, bladder, and esophageal cancer. $A M L$ acute myeloid leukemia, $C L L$ chronic lymphocytic leukemia, $M M$ multiple myeloma

Unfortunately, the mortality rate in the present study was higher than that in cancer patients with COVID-19 in other studies. Also, the mortality rate in all patients with COVID19 in Iran has been reported to be $3.4 \%$ [22] so the mortality rate of this subgroup is much higher than the mortality rate in non-cancer patients with COVID-19. Since most of these patients underwent chemotherapy, drug interferences or the lethality of cancer disease in these patients may be the cause of high mortality.

In this study, 58\% of patients had at least one underlying disease other than cancer. Hypertension, diabetes, and heart disease were the main underlying diseases in

Table 6 Frequency distribution of required therapies in cancer patients with COVID-19

\begin{tabular}{lll}
\hline Treatment & N (\%) & $\begin{array}{l}\text { Hospi- } \\
\text { talization } \\
\text { length } \\
\text { Mean (SD) }\end{array}$ \\
\hline Chemotherapy & $29(69.1)$ & $6.7(3.7)$ \\
Surgery & $4(9.5)$ & $6(4.2)$ \\
Chemoradiotherapy & $3(7.1)$ & $4.3(3.1)$ \\
Mastectomy & $3(7.1)$ & $6.3(4.9)$ \\
Thyroidectomy & $1(2.4)$ & $1(0)$ \\
Radiotherapy & $1(2.4)$ & $11(0)$ \\
$\begin{array}{l}\text { Surgery and chemotherapy and } \\
\text { radiotherapy }\end{array}$ & $1(2.4)$ & $3(0)$ \\
\hline
\end{tabular}


the present study. In the studies carried out by Yang et al. [16], Meng et al. [15], and Tian et al. [14], hypertension, diabetes, and heart disease were the main underlying diseases. In the present study, although having underlying diseases increased the risk of death, none of these diseases had a significant impact on death. Most patients in the present study might have simultaneously other underlying diseases that could increase the rate of mortality in these patients. In some studies, the effect of hypertension and heart disease on death was significant, so that the risk of death increased significantly in these patients [18, 24], although in some studies, such as the present study, the effect of these underlying diseases was not significant level [17].

In the present study, the main symptoms in patients were shortness of breath, fever, chills, muscle pain, dry and sputum cough, and nausea, but only nausea had a significant effect on the survival of these patients. In the study conducted by Sorouri et al. the main clinical symptoms were fever, cough, respiratory problems, and muscle pain, respectively, and only respiratory problems had significant impact on death [17]. In the studies conducted by Yang et al. and Tian et al. the main symptoms of the disease included fever, dry cough, pain, and sputum cough $[14,16]$. In the study conducted by Zhou et al. cough and fever were reported as the most important symptoms of the disease [25]. In some studies, these symptoms have been considered a risk factor for patient survival [9]. In the research carried out by Guarneri et al. fever, respiratory problems, and cough were reported as the most important symptoms, and respiratory problems were the only factor affected the death. Some studies have confirmed this result $[18,24,26]$. The increased incidence of respiratory problems in these patients might be due to the simultaneous involvement of these patients with lung problems. Hence, necessary tests and screenings are needed to identify these symptoms.

In the present study, $19.7 \%$ of patients had leukemia and $80.3 \%$ had other cancers. More than $65 \%$ of patients had leukemia, breast, colorectal, and lung cancers. In the study conducted by Lee, more than $47 \%$ of patients had breast, colorectal, prostate, and lung cancers [18]. Breast, prostate, and colorectal cancers were found in more than 55\% of patients in the study conducted by Carreiraa in the UK [13]. Since the common cancers in different countries are somewhat similar to each other, the similarity in prevalence of this virus in this type of cancers can be justified.

This study demonstrated that, patients with leukemia were at greater risk of death compared to patients with other cancers, but the OR of death was not statistically significant. In a study conducted by Sorouri et al. $42.28 \%$ of patients had leukemia, and $54.7 \%$ of these patients were admitted to the ICU and the mean hospital stay in these patients was 6.2 days [17]. Yang et al. showed that the OR in patients with hematological malignancy was more than 3 times than of patients with solid tumors, and this relationship was significant [16]. In the study conducted by Lee et al. leukemia patients were at greater risk of death than patients with other cancers [18]. The difference between the results of the present study and results of other studies may be attributed to low number of patients with leukemia in this study. In addition, patients with leukemia were identified in milder conditions than patients with other cancers in the present study, so that the number of leukemia patients need to be admitted to ICU was lower than the number of other cancers ( $23.1 \mathrm{vs.} 41.5 \%$ ).

In the present study, the risk of death in patients admitted to ICU was 12.58 times than of patients admitted to the ward. In addition, the risk of death increased by 26 times in patients admitted to both ICU and the normal wards. In a study conducted by Guarneri, the risk of death in ICU patients increased by 9 times [12]. In the study conducted by Lee et al. the mortality rate in ICU patients increased by 2.73 times [18].

In this study, $95.5 \%$ of patients received oxygen therapy, $37.5 \%$ were admitted to ICU, and $34.8 \%$ received mechanical ventilation. The risk of death in people who had mechanical ventilation in addition to oxygen therapy increased by 7.45 times, and in patients who received all the three procedures, the risk of death was 33.6 times higher than in patients who received only oxygen therapy. In the study conducted by Yang, $73 \%$ received oxygen therapy, $15 \%$ received mechanical ventilation, and $15 \%$ were admitted to ICU [16]. In the study conducted by Guarneri, 35\% received oxygen therapy and $17 \%$ received mechanical ventilation [12]. In Lee et al. the risk of death in patients with mechanical ventilation increased by 2.73 times [18]. Although the use of mechanical ventilation has been recommended to reduce the risk of death, especially in patients with respiratory problems [25, 26], in the present study out of 23 patients who needed mechanical ventilation, only one patient survived and the rest died.

Present study showed that, nonstandard results of laboratory tests in all measured characteristics increased the risk of death, but only the variable of LDH had a statistically significant effect on death in patients, so that it increased the risk of death by 2.89 times. In the study conducted by Yang et al. as in the present study, most of the characteristics had a significant effect on increasing the OR of death in patients and the variable of $\mathrm{LDH}$ increased the risk of death by 2.8 times [16].

In Guarneri et al. LDH increased the risk of death, but the effect of this variable was not significant [12]. Also, Tian et al. showed that the effect of LDH was significant [14]. The intracellular enzyme of LDH is widely found in most tissues of body. This enzyme level increases usually after cell death and the release of this enzyme into the bloodstream. Although LDH is not a specific test alone, its increase along with other clinical signs and additional tests is useful in diagnosing chronic obstructive pulmonary disease (COPD), muscular dystrophy, and pernicious anemia. High levels of 
LDH in the blood can indicate tissue damage to lungs and lung cells and thus increase death. One limitation of the present study was missing observations in some clinical and laboratory characteristics or lack of measurement of some important characteristics in this study. In addition, due to the small number of sample, it was impossible to perform multivariate analysis to evaluate the effect of factors on treatment outcomes in patients.

\section{Conclusion}

Cancer patients with COVID-19 may experience more severe form of this disease, since they suffer other underlying diseases. Hence, they need special care and need to receive specific cancer-related treatments. Therefore, the mortality rate in this group of vulnerable population is expected to be much higher than the general population. However, screening of these patients and timely identifying and vaccinating of them can reduce the mortality rate in these patients.

Acknowledgements We would like to thank the Deputy of Research of Hamadan University of Medical Sciences for his supports of this study. The proposal of this study was approved by the Institutional review board (IRB) of Hamadan University of medical sciences (ethical code: IR.UMSHA.REC.1400.004).

Author Contribution MS and GR and JF designed the study and analyzed the data. MS and GR wrote the original draft with support from SB and AS. Both SK and JF authors contributed to the interpretation of the results. SB, AS, and SK contributed in methodology of study and preparation of patient's information and data collection. All authors contributed to the final version of the manuscript and approved the final version of the manuscript.

Code Availability SPSS24 software.

\section{Declarations}

Ethics Approval The proposal of this study was approved by the Institutional Review Board (IRB) of Hamadan University of Medical Sciences (ethical code: IR.UMSHA.REC.1400.004, project no: 14000207892).

Consent to Participate Informed consent was obtained from all individual participants included in the study.

Consent to Publication All individual participants included in the study gave their informed consent for the inclusion in the study and for publication of the manuscript.

Conflict of Interest The authors declare no competing interests.

\section{References}

1. Zhu N, Zhang D, Wang W, Li X, Yang B, Song J, Zhao X, Huang B, Shi W, Lu R, Niu P, Zhan F, Ma X, Wang D, Xu W, Wu G, Gao GF, Tan W. China novel coronavirus investigating and research team. A novel coronavirus from patients with pneumonia in china, 2019. N Engl J Med. 2020; 382(8):727-733.
2. Ge H, Wang X, Yuan X, Xiao G, Wang C, Deng T, Yuan Q, Xiao $X$. The epidemiology and clinical information about COVID-19. Eur J Clin Microbiol Infect Dis. 2020; 39(6):1011-1019. https:// www.who.int/emergencies/diseases/novel-coronavirus-2019/ events-as-they-happen.

3. Ministry of Health and Medical Education, Public Relations and Information Center. [Death of two patients with new coronavirus in Qom]. Tehran: MoHME; 2020. [Updated 2020 Feb 19; cited $2020 \mathrm{Feb}$ 19]. Available from: https://cutt.ly/etW0SIQ.

4. Bow EJ. There should be no ESKAPE for febrile neutropenic cancer patients: the dearth of effective antibacterial drugs threatens anticancer efficacy. J Antimicrob Chemother. 2013;68:492-5.

5. Azoulay E, Mokart D, Lambert J, et al. Diagnostic strategy for hematology and oncology patients with acute respiratory failure: randomized controlled trial. Am J Respir Crit Care Med. 2010;182:1038-46.

6. Azoulay E, Lemiale V, Mokart D, et al. Acute respiratory distress syndrome in patients with malignancies. Intensive Care Med. 2014;40:1106-14.

7. Zheng YY, Ma YT, Zhang JY, Xie X. COVID-19 and the cardiovascular system. Nat Rev Cardiol. 2020;17:259-60.

8. Liang W, Guan W, Chen R, et al. Cancer patients in SARSCoV-2 infection: a nationwide analysis in China. Lancet Oncol. 2020;21(3):335-7.

9. Zhang L, Zhu F, Xie L, Wang C, Wang J, Chen R, et al. Clinical characteristics of COVID-19-infected cancer patients: a retrospective case study in three hospitals within Wuhan. China Ann Oncol. 2020;31(7):894-901.

10. Miyashita H, Mikami T, Chopra N, Yamada T, Chernyavsky S, Rizk D, Cruz C. Do patients with cancer have a poorer prognosis of COVID-19? An experience in New York City. Ann Oncol. 2020;31(8):1088-9.

11. Guarneri V, Bassan F, Zagonel V, Milellae M, Zaninelli M, Maria A, et al. Epidemiology and clinical course of severe acute respiratory syndrome coronavirus 2 infection in cancer patients in the Veneto Oncology Network: The Rete Oncologica Veneta covID19 study. Eur J Cancer. 2021;147:120-7.

12. Carreiraa H, Strongmana H, Peppa M, McDonald HI, dos-SantosSilva I, Stanway S, et al. Prevalence of COVID-19-related risk factors and risk of severe influenza outcomes in cancer survivors: A matched cohort study using linked English electronic health records data. E Clinical Medicine. 2020; 29-30:100656.

13. Tian J, Yuan X, Xiao J, et al. Clinical characteristics and risk factors associated with COVID-19 disease severity in patients with cancer in Wuhan, China: a multicentre, retrospective, cohort study. Lancet Oncol. 2020;21(7):893-903.

14. Meng Y, Lu W, Guo E, et al. Cancer history is an independent risk factor for mortality in hospitalized COVID-19 patients: a propensity score-matched analysis. J Hematol Oncol. 2020;13(1):75.

15. Yang K, Sheng Y, Huang C, Jin Y, Xiong N, Jiang K, et al. Clinical characteristics, outcomes, and risk factors for mortality in patients with cancer and COVID-19 in Hubei, China: a multicentre, retrospective, cohort study. Lancet Oncol. 2020;21(7):904-13.

16. Sorouri M, Kasaeian A, Mojtabavi H, Radmard AR, Kolahdoozan $\mathrm{S}$, Anushiravani A, et al. Clinical characteristics, outcomes, and risk factors for mortality in hospitalized patients with COVID-19 and cancer history: a propensity score-matched study. Infect Agent Cancer. 2020;15(1):74.

17. Lee LYW, Cazier JB, Starkey T, Turnbull C, Team UCCMP, Kerr $\mathrm{R}$, et al. COVID-19 mortality in patients with cancer on chemotherapy or other anticancer treatments: a prospective cohort study. Lancet. 2020; 395(10241):1919-1926.

18. Sung H, Ferlay J, Siegel RL, Laversanne M, Soerjomataram I, Jemal A, Bray F. Global cancer statistics 2020: GLOBOCAN estimates of incidence and mortality worldwide for 36 cancers in 185 countries. CA Cancer J Clin. 2021;71(3):209-49. 
19. Elfaituri MK, Morsy S, Tawfik GM, Abdelaal A, El-Qushayri $\mathrm{AE}$, Faraj HA, et al. Incidence of infection-related mortality in cancer patients: trend and survival analysis. J Clin Oncol. 2019;37(15):e23095-e23095. https://doi.org/10.1200/JCO.2019. 37.15_suppl.e23095.

20. Omarini C, Maur M, Luppi G, Narni F, Luppi M, Dominici M, et al. Cancer treatment during the coronavirus disease 2019 pandemic: do not postpone, do it! Eur J Cancer. 2020; 133:29-32. https://www.coronatracker.com/country/iran.

21. Yarza R, Bover M, Paredes D, López-López F, Jara-Casas D, Castelo-Loureiro A, et al. SARS-CoV-2 infection in cancer patients undergoing active treatment: analysis of clinical features and predictive factors for severe respiratory failure and death. Eur J Cancer. 2020;135:242-50.

22. Garassino MC, Whisenant JG, Huang L-C, Trama A, Torri V, Agustoni F, et al. COVID-19 in patients with thoracic malignancies (TERAVOLT): first results of an international, registry-based, cohort study. Lancet Oncol. 2020;21(7):914-22.
23. Zhou F, Yu T, Du R, et al. Clinical course and risk factors for mortality of adult inpatients with COVID-19 in Wuhan, China: a retrospective cohort study. Lancet. 2020;395(10229):1054-62.

24. Guan WJ, Ni ZY, Hu Y, et al. Clinical characteristics of coronavirus disease 2019 in China. N Engl J Med. 2020;382(18):1708-20.

25. Joyner MJ, Carter RE, Senefeld JW, et al. Convalescent plasma antibody levels and the risk of death from Covid-19. N Engl J Med. 2021; 384(11):1015-1027.

26. Tomazini BM, Maia IS, Cavalcanti AB, et al. Effect of dexamethasone on days alive and ventilator-free in patients with moderate or severe acute respiratory distress syndrome and COVID-19: The CoDEX Randomized Clinical Trial. JAMA. 2020;324(13):1307-16.

Publisher's Note Springer Nature remains neutral with regard to jurisdictional claims in published maps and institutional affiliations. 